\title{
PRODUCT MANAGEMENT FOR INDUSTRIAL PRODUCT SERVICE SYSTEMS: A MODEL TOWARDS THE UNDERSTANDING OF THE ROLE OF PRODUCT MANAGEMENT
}

\author{
Marina Brunner and Christian Schieder \\ Technical University of Applied Sciences Amberg-Weiden \\ Hetzenrichter Weg 15, 92637 Weiden, Germany
}

\begin{abstract}
Due to increasing competition and new consumer trends, the importance of innovation for industrial product service system is continuously increasing. Industrial companies must constantly come up with new ways to differentiate themselves from cheaper competitors, which also increases the complexity of product management tasks. In this paper, we aim to improve the understanding of the individual tasks of product management in an industrial environment, to identify their interrelationships and to measure and optimize the quality of the executed processes. In total, we defined 22 different industrial product management tasks along the product lifecycle, determined by five maturity levels within 14 maturity dimensions for each object. Subsequently, the model was tested in several industrial companies. Initial validations of the model's structure and content show that the model is transparent, easy to use, and has proven its applicability in real business environments.
\end{abstract}

KEYWORDS

Product Management, Maturity Model, Industrial Product Service Systems, Design Science Research

\section{INTRODUCTION}

Globalization and increasing international competition mean that companies need to innovate products and processes in order to continue to withstand rising cost and time pressures (Großmann et al. (2015)). As a result of the increasingly global division of labor, the complexity of work organization has increased. In addition, complex customer requirements and the trend toward product customization pose major challenges for companies (Großmann et al. (2015); Helo et al. (2017)). New product variants have to be developed, tested, documented and supported once. This situation leads to more resources, increased workload, and difficulties in implementing product roadmaps. Only companies that follow a market-oriented production approach are successful in the long run. The implementation of such processes requires a lot of discipline and commitment and, above all, competent employees (Steinhardt (2017)). Therefore, a company must coordinate these processes in order to develop customer-oriented products, bring them successfully to market, and optimize the product life cycle.

The product manager plays an increasingly important role in the sustainable development of products. Product managers must plan, implement, and control all product-related activities in a goal-oriented manner as part of a systematic management process (Stark (2018); Dawid et al. (2017)). However, compared to other areas, there is a lack of understanding of the tasks of product management. As a result, the scope of product management is defined and lived differently from company to company, making it difficult to compare and optimize processes. A correct definition and structuring of the roles and tasks of product management would lead to a more efficient and productive use of company resources, resulting in better yields and higher quality products (Steinhardt (2017)). 
Therefore, the goal of this work is to develop a maturity model that evaluates whether product management and its functionality are suitable to support the complexity of the management processes of product service systems. A maturity model comprises a sequence of maturity levels for a class of objects and thus describes the desired development path of these objects. Progress along this development path usually means a steady increase in the performance or quality of the object (Pöppelbuß et al. (2011); Mettler (2010)).

\section{THEORETICAL BACKGROUND}

\subsection{Product Management}

Product management (PM) is a management concept that ensures product-related task structuring while maintaining functional structures. PM coordinates all product-related topics for products or product groups across all functional areas. It is thus an information, coordination, and control platform for all product-related topics inside and outside the company (Behrens et al. (2014); Pranam (2018)).

Over time, the role of product management in the corporate context has been redefined again and again (Behrens et al. (2014)). Similar to professional fields such as program and project management or product development, product management emerged from the defense industry in the United States after World War II. The field of product management is still misinterpreted today, which is why it needs a more precise definition. A specifically defined scope would ensure better execution, optimization and comparability of processes, roles and tasks in the future (Steinhardt (2017)).

\subsection{Industrial Product Service Systems}

For a long time, industrial manufacturers were able to hold their own in the market by offering technically and qualitatively superior products. In recent years, however, the framework conditions that can generate competitive advantages have changed. Products are becoming increasingly similar as a result of globalization, and price is becoming the decisive purchasing criterion for physical products. More and more industrial companies are responding to this change by supplementing physical products with accompanying service components. Companies that embrace this development can expect higher customer loyalty, increased revenue streams, stable sales, and new customer segments (Helo et al. (2017); Behrens et al. (2014); Schweitzer et al. (2010); Song (2019)). The so-called product service system manufacturers offer lifecycle-oriented service products that effectively support customers in the use of physical products. Customer support is thus ensured throughout the entire life cycle of the products. With an appropriate IT infrastructure, companies can also continuously gain information about the use of the physical products, the customers and the current market situation (Schweitzer et al. (2010)).

Industrial product service systems (IPSS) consist of product and service components that together meet customer needs in an industrial business-to-business context. The product components can be mechanical, electronic, or software (Großmann et al. (2015); Helo et al. (2017)). The service components may change depending on the life cycle phase. The design and implementation of IPSS takes place within the extended value network of the IPSS provider, while the production network includes, for example, suppliers of parts for manufacturing. The service network is responsible for providing service products and consists of the subsidiaries, contract and service partners. Above all, the network and infrastructure are specific characteristics for IPSS (Schweitzer et al. (2010); Ceschin (2014)).

\section{RESEARCH APPROACH}

According to Becker et al. (2009), a maturity model can be considered an artifact and is therefore subject to the principles of design-oriented research. The Design Science Research (DSR) approach was chosen because it has the potential to bridge the gap between theory and practice by both solving practical problems and generating knowledge that can be used as a basis or to improve scientific theories. 
Becker et al. (2009) provide the following requirements for developing a maturity model: (1) comparison with existing maturity models, (2) iterative approach, (3) evaluation, (4) multi-method approach, (5) evidence of problem relevance, (6) problem definition, (7) provision of results appropriate to the target audience, (8) scientific documentation. Figure 1 shows how the requirements are adapted in the development of this maturity model.

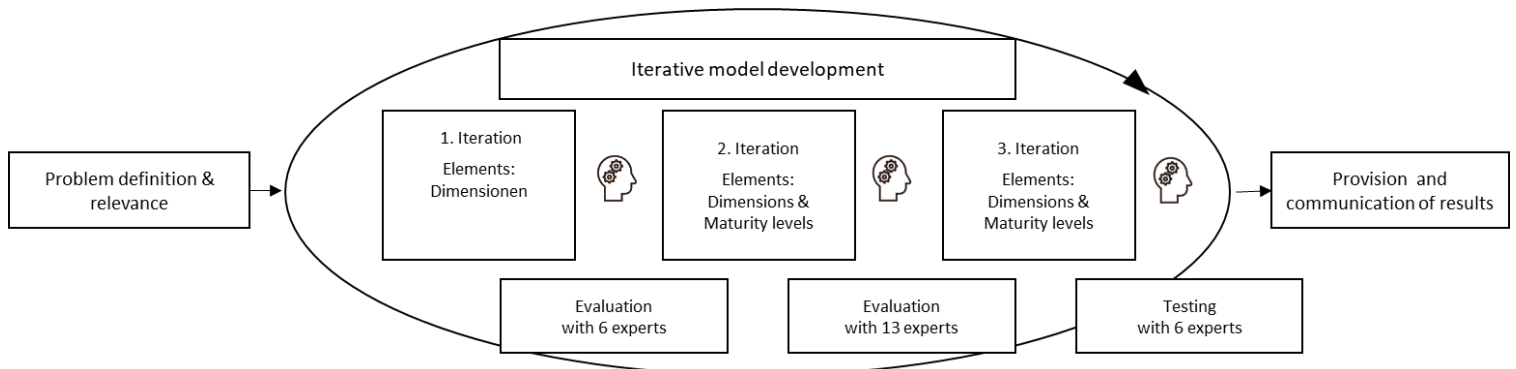

Figure 1. Iterative development of the maturity model

\section{METHODOLOGY}

\subsection{Literature Research}

The basis for the development of this maturity model for IPSS product management is a systematic literature review based on the specifications of Vom Brocke et al. (Vom Brocke et al. (2015)). The literature review serves as a basis for the definition of the product management task areas and the subsequent determination of the maturity levels. Table 1 shows the flow of the applied method.

For this thesis, it was decided to use an iterative search process. In this process, the literature search is continued and repeated several times. Since this thesis uses a design science research approach, an iterative approach is preferred over a sequential one. In this work, free services such as Google Scholar, publication databases, such as ScienceDirect, AISeL, Emerald Insight, and university libraries have been used. Covering the topic of product management of product service systems is laborious, as there is little accessible literature on this particular topic. Therefore, it was not possible to build on similar work or on seminal work in this area. Nevertheless, a representative literature review, based on the individual components of the topic, was conducted. To ensure representativeness, the defined tasks of PM had to be described by different sources (Vom Brocke et al. (2015)). This procedure resulted in 41 publications and books that were evaluated by the researchers.

\subsection{Expert Interviews}

In addition to the information derived from the literature review, the iterative nature of the DSR approach allows us to include further insights from expert interviews. In this work, expert interviews are used to review the state of research on product management for product service systems and to extract relevant information that has not yet been addressed in the literature (Wilberg et al. (2017)). As part of the research project, we collected and analyzed the opinions of 25 experts through semi-structured interviews and expert surveys.

The first six interviews provided overarching insights into the scope of product management for IPSS. The insights from the following 13 expert interviews were collected through a survey to verify the quality of the maturity model based on the criteria explained in Chapter 6. The remaining 6 experts tested the optimized maturity model in their company's product management. 
Table 1 provides an overview of the interview partners (IP) and their background. Listed are the number of experts in chronological order, their current position, their area of experience, a distinction between physical products (PP), services $(\mathrm{S})$ and software products $(\mathrm{SW})$, their experience with product management or product service systems in years and the industry in which they work.

Table 1. Overview of expert's background

\begin{tabular}{lllll}
\hline IP & Position & Area of Experience & Experience in years & Industry \\
\hline & & \multicolumn{1}{c}{ 1. Iteration } & & \\
1 & Head of Product Management & $\mathrm{PP}$ & 2 & Machine construction \\
2 & Head of Product Management Lifecycle & $\mathrm{S}$ & 10 & Machine construction \\
3 & Product manager & $\mathrm{PP} / \mathrm{S}$ & $3 \mathrm{1} / 2$ & Components construction \\
4 & Product management consultant & $\mathrm{PP}$ & 20 & Consulting \\
5 & Professor & $\mathrm{S}$ & 10 & Education \\
6 & General Manager & $\mathrm{PP}$ & 5 & Components construction \\
& & $\mathrm{2.}$ Iteration & & \\
7 & Junior Product Manager & $\mathrm{PP} / \mathrm{SW}$ & 3 & Automation \\
8 & Product Manager & $\mathrm{SW}$ & 4 & Wellness SaaS \\
9 & Product Manager B2C & $\mathrm{S}$ & 5 & Utilities \\
10 & Industry Strategy Manager & $\mathrm{PP} / \mathrm{SW} / \mathrm{S}$ & 12 & Industrial automation \\
11 & Industry Portfolio Manager & $\mathrm{PP}$ & 10 & Industrial automation \\
12 & Industry Strategy Manager & $\mathrm{PP}$ & 9 & Industrial automation \\
13 & Strategic Incubation Manager & $\mathrm{SW} / \mathrm{S}$ & 1 & Industrial automation \\
14 & Product Manager & $\mathrm{PP}$ & 3 & Furniture industry \\
15 & Head of Product Management & $\mathrm{PP}$ & 3 & Industrial automation \\
16 & Industry Management & $\mathrm{PP}$ & 20 & Electrical industry \\
17 & Product Manager & $\mathrm{PP} / \mathrm{S}$ & 30 & Automobile \\
18 & Product Manager & $\mathrm{PP} / \mathrm{SW} / \mathrm{S}$ & 10 & Industrial automation \\
19 & Product Manager & $\mathrm{S}$ & 22 & Automobile \\
& & 3. Iteration & & \\
20 & Product Manager & $\mathrm{PP}$ & 5 & Food \\
21 & Product Manager & $\mathrm{PP}$ & 5 & Electrical \\
22 & Product Owner & $\mathrm{S}$ & $\mathrm{S}$ & Service industry \\
23 & Product Manager & $\mathrm{PP} / \mathrm{SW} / \mathrm{S}$ & 7 & Insurance \\
24 & Head of Product Management & $\mathrm{PP} / \mathrm{SW} / \mathrm{S}$ & 3 & Machine construction \\
25 & Industry Strategy Manager & & & Media \\
& & & 6 &
\end{tabular}

\section{ARTEFACT DESCRIPTION}

\subsection{Definition of Tasks of Product Management}

The development and management process of product service systems encompasses all lifecycle phases. Product management represents a cross-functional organizational unit that accompanies the development and management from the creation to the execution of the product. To get a better overview of the scope of all critical product management tasks, the tasks are assigned chronologically to the different lifecycle phases (see Figure 2). The final model contains 22 tasks that are relevant for the product management of industrial product service systems. 


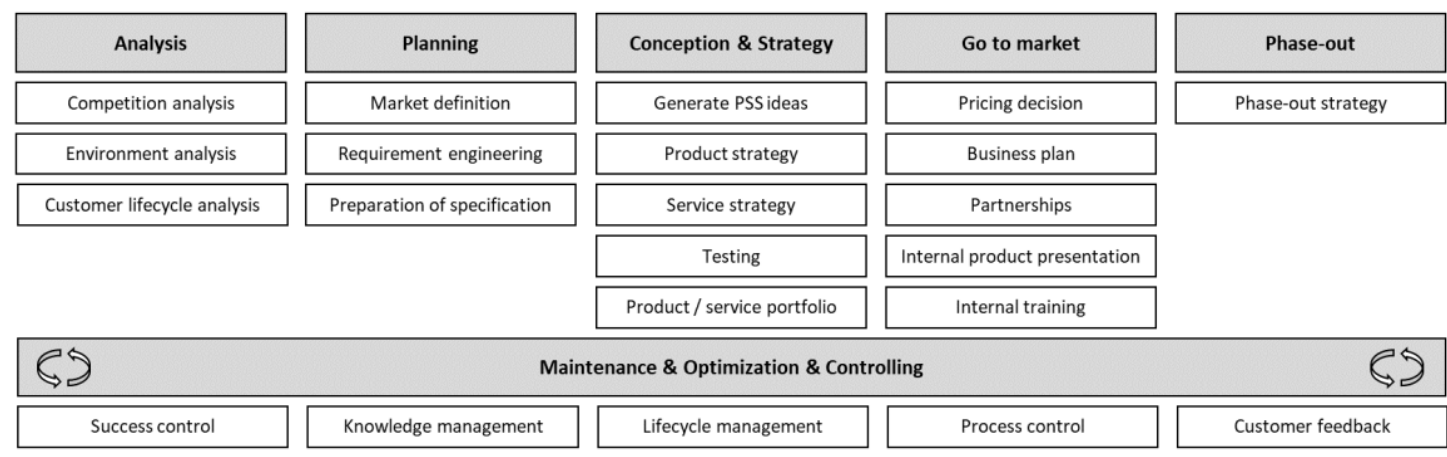

Figure 2. Objects of the maturity model

\subsection{Definition of Maturity Levels for Product Management}

The essential elements of a maturity model are the various maturity levels at which the quality of the object of investigation is assessed. Depending on the model, four to six different maturity levels are usually defined. As already mentioned, this work examines the quality of the tasks performed by product management. For this reason, a maturity model that measures the quality of the processes is suitable. A successful process flow depends on various criteria (Hammer et al. (2007)). Most maturity models work with cumulative maturity levels that contain several criteria. Since product management is a very practical business domain, this work focuses on the problem adequacy of the model. Cumulative maturity levels can lead to confusion in practical applications, as rarely all criteria of a maturity level are met. Therefore, assignment to a particular maturity level can be difficult. In addition, a cumulative assessment can lead to the risk that the cause of the process problem cannot be clearly identified when analyzing the problems later.

Therefore, the maturity levels for this model are divided into different criteria. The criteria, referred to below as maturity dimensions, were derived from existing business process maturity models. It was possible to identify 14 process maturity dimensions. And it was found that not every dimension has five maturity levels. Some dimensions require a certain basic structure to be applied by companies, such as optimization. Most companies optimize their processes only after they have already established a structured process. Other dimensions play a significant role only in the first stages of maturity, such as the need for action, which is an important process driver at the beginning but usually cannot be improved further once it is established. The distribution and definition of dimensions and maturity levels is shown in Figure 3. The following dimensions are used to assess the maturity level of the individual product management tasks: Need for Action (NfA), Frequency of Execution (FoE), Standardization (Stand), Documentation (Doc), Measure and Control (M\&C), Process Context (ProCon), Optimization (Opt), Skills, Training (Train), Networking and Communication (N\&C), Tool Usage (TU), Key Performance Indicator (KPI), Adaptation and Agility (Adapt), and IT Infrastructure (IT).

NfA describes the extent to which an organization sees the need to accomplish the task. The FoE dimension measures the frequency with which the task is performed. State and Doc describe the extent to which the task is standardized and documented. The M\&C dimension gives an impression of the extent to which the execution of the task is measured and controlled. ProCon measures the employees' understanding of the process context in which the task is embedded and which other areas are affected by its execution. Opt shows the optimization opportunities applied. The Skills and Train dimensions refer to the skills of the employees and the extent to which they are trained for the task. N\&C refers to interdisciplinary networking to solve the task within the company and the communication of important information across companies. TU and IT describe whether and to what extent tools are used and how well the IT infrastructure is developed. The KPI dimension measures the use and quality of the metrics used. Adapt gives an indication of how quickly the company reacts to changes in the market or the competition. 


\begin{tabular}{|c|c|c|c|c|c|}
\hline & Maturity level 1 & Maturity level 2 & Maturity level 3 & Maturity level 4 & Maturity level 5 \\
\hline Need for action & Necessary & $\begin{array}{l}\text { Relevant in entrie } \\
\text { organization }\end{array}$ & & & \\
\hline $\begin{array}{l}\text { Frequency of } \\
\text { execution }\end{array}$ & Ad-hoc & More often & Regular & & \\
\hline Standardization & Unstructured & Person-dependent & $\begin{array}{c}\text { Completely defined \& } \\
\text { standardized }\end{array}$ & Formulated objectives & \\
\hline Documentation & & Basic & Consistent \& complete & Formulated objectives & $\begin{array}{l}\text { Electronic process } \\
\text { workflow }\end{array}$ \\
\hline $\begin{array}{l}\text { Measurement and } \\
\text { controlling }\end{array}$ & & Informal & $\begin{array}{c}\text { Formal on functional } \\
\text { level }\end{array}$ & $\begin{array}{c}\text { Cross-functional \& } \\
\text { Transparent }\end{array}$ & $\begin{array}{l}\text { Electronic process } \\
\text { workflow }\end{array}$ \\
\hline Process context & Department focused & Limited & Focus company-wide & Controlled subprocess & $\begin{array}{l}\text { Management accross } \\
\text { ecosystem }\end{array}$ \\
\hline $\begin{array}{l}\text { Optimization } \\
\text { potential }\end{array}$ & & & & $\begin{array}{c}\text { Initiation of } \\
\text { Countermeasures }\end{array}$ & Self-adaptive process \\
\hline Skills & Little or no & Limited & Effectively & Advanced & Mentor \& Innovator \\
\hline Training & & Informal & Formal & Accreditated & Organizational learning \\
\hline $\begin{array}{l}\text { Networking and } \\
\text { communication }\end{array}$ & & Informal & Formal & Regularly & $\begin{array}{c}\text { Network \& Work } \\
\text { groups }\end{array}$ \\
\hline Tool usage & Sporadically & Limited & Documented & $\begin{array}{c}\text { Tool quality measured } \\
\text { \& optimized }\end{array}$ & \\
\hline KPIs & & Simple & $\begin{array}{c}\text { Process } \\
\text { comprehensive }\end{array}$ & Strategically derived & Industry-driven \\
\hline Adaption \& Agility & $1-2$ years & 1 year & Few month & Few weeks & Predictive \\
\hline IT infrastructur & & Fragmented & Consistent & $\begin{array}{l}\text { Ensures compliance } \\
\text { with standards }\end{array}$ & Automated \\
\hline
\end{tabular}

Figure 3. Overview of maturity levels

\section{EVALUATION}

Becker et al. plan for this step to check and evaluate the developed results for completeness, consistency, and problem adequacy (Pöppelbuß et al. (2011)). The participants of the second evaluation assessed the existing model within the assessment dimensions quality of the objects, quality of the maturity levels, quality of the maturity model, and quality of problem solving (Pöppelbuß et al. (2011)) (Dresch et al. (2015)). The criteria to be evaluated can be seen in figure 4 .

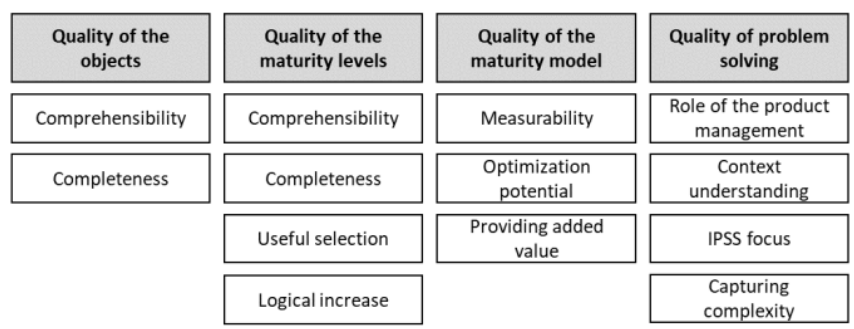

Figure 4. Overview of evaluation criteria

The experts assessed the maturity model as a consistent tool for evaluating product management for industrial product-service-systems. Many of the requirements are already satisfactorily fulfilled in the status quo.

Furthermore, the model was used by six other experts as proof of feasibility. The company received a questionnaire per e-mail to allow for reflected assessment of their internal situation on their own time. Nevertheless, it should be borne in mind that mere implementation cannot provide proof of an increase in the 
quality of product management for IPSS as a result of implementing the model. Such proof would require, on the one hand, a larger and longer-term test phase and, on the other hand, the definition of key figures to measure success. The purpose of this test is to determine the current status in the area of product management maturity in order to be able to make statements about the applicability of the model.

Network diagrams are used to present the overall result at a glance. Visualization in the form of a network diagram provides an overview of the maturity distribution of the individual object within the 14 different maturity dimensions. Companies can thus identify gaps in process performance for each individual task. To provide an overview of the differences between the companies in the evaluation, the results of the six companies for the object "competition analysis" are analyzed in more detail below.

The gray line shows the maximum achievable maturity level for each dimension. None of the six companies achieves the highest level in all maturity dimensions. Within the individual company results, strong differences can be seen in the assessment of the various maturity dimensions. For example, company 6 rates the competitive analysis process at levels 3 and 4 in the optimization, capabilities and tool use dimensions, while the measurement and controlling and adaptation to market conditions dimensions are rated as non-existent (level 0). This trend is also reflected in the maturity rating of the other objects. This approach enables a differentiated and detailed presentation. In further investigations, more concrete recommendations for action can be derived than with the cumulative maturity measurement.

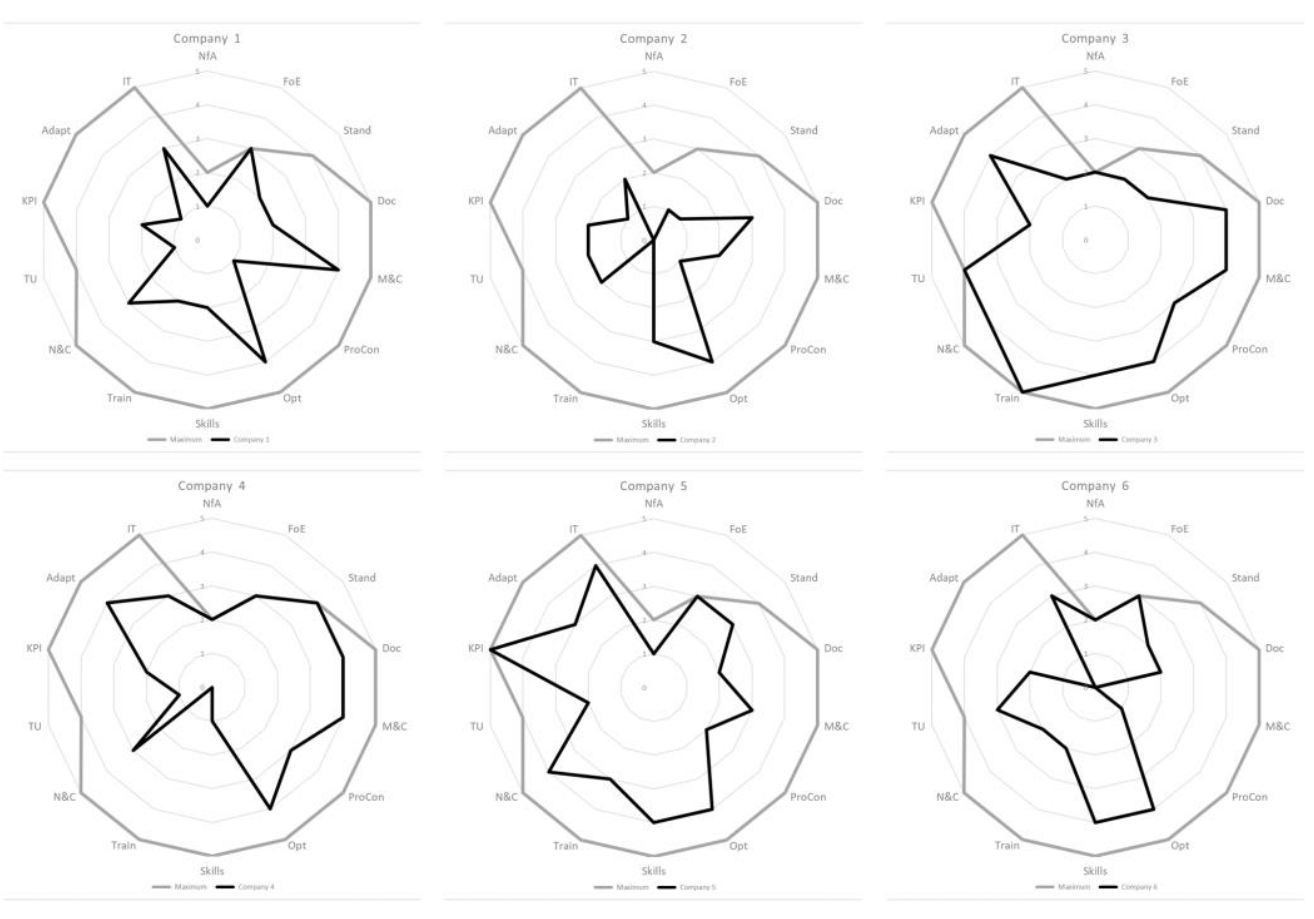

Figure 5. Overview of the evaluation results for the task "competition analysis"

\section{CONCLUSION}

As part of the study, a complete maturity model was created through several iterations. This study was conducted to develop a model to facilitate the assessment and improvement of product management maturity of industrial product service systems. Many models exist in the literature to facilitate the assessment or improvement of business process management maturity. Such models prove to be most effective when specialized for a particular business domain. While many general maturity models are available in the literature, no product management-specific model has been found. To support the improvement of product management maturity for industrial product service systems and thereby contribute to the understanding of the role of product management and the quality of IPSS, a new maturity model was developed. 
The model was developed using various scientific methods. Through literature review, expert interviews, and surveys, data was collected on the possible structure and content of a product management maturity model. The final model contains 22 tasks that are relevant for product management of industrial product service systems. These objects can be measured along different maturity levels. The maturity levels have 14 dimensions and between two and five maturity levels depending on the dimension. Assessing product management along the maturity model provides an overview of the domain's maturity level, which identifies areas for improvement. This assessment helps to create awareness of current problems in product management and provides the starting point for future improvements. Thus, the model can help to achieve better quality of industrial product service systems. In view of this, the development of the model fulfills both organizational and scientific requirements and answers the previously posed research questions.

\section{REFERENCES}

Behrens, B.; Nyhuis, P.; Overmeyer, L.; Bentlage, A.; Rüther, T.; Ullmann, G.: Towards a definition of large scale products. In: Prod. Eng. Res. Devel. 8 (1-2), S. 153-164. (2014)

Ceschin, F.: Sustainable product-service systems. Between strategic design and transition studies. Cham: Springer International Publishing (2014)

Dawid, H.; Decker, R.; Hermann, T.; Jahnke, H.; Klat, W.; König, R.; Stummer, C.: Management science in the era of smart consumer products. Challenges and research perspectives. In: Central European Journal of Operations Research 25 (1), S. 203-230 (2017)

Dresch, A.; Lacerda, D.; Antunes Júnior, J.: Design science research. A method for science and technology advancement. Cham: Springer International Publishing. (2015)

Großmann, D. J.; Kasperek, D.; Stahl, B.; Lohmann, B.; Maurer, M.: Supporting IPSS Innovation Processes by an Integrating Model Grid. In: Procedia CIRP 30, S. 227-232. (2015)

Hammer, M.: The Process Audit. A new framework, as comprehensive as it is easy to apply, is helpingcompanies plan and execute process-based transformations. Harvard Business Review, Vol. 85 No. 4, pp. 111-23. (2007)

Helo, P.; Gunasekaran, A.; Rymaszewska, A.: Designing and Managing Industrial Product-Service Systems. Cham.: Springer International Publishing (2017)

Mettler, T.: Thinking in Terms of Design Decisions When Developing Maturity Models. In: International Journal of Strategic Decision Sciences 1 (4), S. 76-87. (2010)

Pöppelbuß, J.; Röglinger, M.: What makes a useful maturity model? a framework of general design principles for maturity models and its demonstration in business process management. paper presented at 19th European Conference on Information Systems. (2011)

Pranam, A.: Product management essentials. Tools and techniques for becoming an effective technical product manager. Berkeley, California, New York, Springer Science (2018)

Schuh, G.; Rozenfeld, H.; Assmus, D.; Zancul, E.: Process oriented framework to support PLM implementation. In: Computers in Industry 59 (2-3), S. 210-218. (2008)

Schweitzer, E.; Aurich, J. C.: Continuous improvement of industrial product-service systems. In: CIRP Journal of Manufacturing Science and Technology 3 (2), S. 158-164 (2010)

Song, W.: Customization-Oriented Design of Product-Service System. Singapore: Springer Singapore. (2019)

Stark, J.: Product Lifecycle Management (Volume 3): The Executive Summary. Cham: Springer International Publishing (2018)

Steinhardt, G.: The product manager's toolkit. Methodologies, processes and tasks in high-tech product management. Second edition. Cham, Switzerland: Springer (2017)

Vom Brocke, J.; Simons, A.; Riemer, K.; Niehaves, B.; Plattfaut, R.; Cleven, A.: Standing on the Shoulders of Giants: Challenges and Recommendations of Literature Search in Information Systems Research. In: Communications of the Association for Information Systems 8-2015 // 37. (2015)

Wilberg, J.; Schafer, F.; Kandlbinder, P.; Hollauer, C.; Omer, M.; Lindemann, U.: Data analytics in product development: Implications from expert interviews (IEEE International Conference on Industrial Engineering and Engineering Management (IEEM)), S. 818-822 (2017) 